\title{
The Story is in the Structure: A Multi-Case Study of Instructional Design Teams
}

\author{
Jason Drysdale \\ University of Colorado
}

\begin{abstract}
Although instructional designers are experienced and positioned to be leaders in online learning, it was not previously known how organizational structures influenced their ability to act as leaders in their institutions. This problem warranted a deep exploration of the organizational structures for instructional design teams in higher education. This qualitative, multi-case study consisted of three individual universities each with a different organizational structure profile. Data were collected through semi-structured interviews and document analysis with participants in three key roles at each institution: dedicated instructional designer, online faculty member, and online learning administrator. The research culminated in within-case analyses of each institution and a comparative case analysis of all three studied institutions. The results of the study revealed that the organizational structure that most positively influenced instructional design leadership was a centralized instructional design team with academic reporting lines. Decentralized instructional designers experienced significant disempowerment, role misperception, and challenges in advocacy and leadership, while instructional designers with administrative reporting lines experienced a high level of role misperception specifically related to technology support. Positional parity between dedicated instructional designers and faculty, in conjunction with implementation of the recommended organizational structure, was found to be critical to empowering designers to be partners and leaders.
\end{abstract}

Keywords: organizational structure, instructional design, online learning, leadership, shared governance, program design, centralization, decentralization

Drysdale, J. (2021). The story is in the structure: A multi-case study of instructional design teams. Online Learning, 25(3), 57-80. doi:10.24059/olj.v25i3.2877 
Online learning is now a ubiquitous format for learners across the United States (Allen \& Seaman, 2016). It is a priority for most university administrators, with $72 \%$ of online learning leaders indicating that initiatives such as developing new online programs act as "catalysts for change" (Fredericksen, 2017, p. 10). Dedicated, full-time instructional designers are uniquely equipped to lead such online learning initiatives and have a different and complimentary lens of expertise than university faculty (Shaw, 2012).

Instructional designers in higher education are experts in pedagogy; course design and development; teaching with technology; and a host of related skills and practices. They often work alongside faculty to create and redesign courses, equip faculty with new skills through workshops and professional learning, and provide expert coaching on the unique experience of teaching and learning in a digital environment. Instructional designers also conduct and participate in research on teaching and learning (Beirne \& Romanoski, 2018). During the early days of the COVID-19 pandemic, online learning professionals, including instructional designers, led the way in distinguishing intentionally designed online learning from emergency remote learning, a frequent designation for courses offered through a rapid shift to digital environments (Hodges et al., 2020). Instructional design teams shifted from a preferred institutional resource to a necessary one.

Instructional designers work in a wide variety of organizational structures, varying from institution to institution across a range of different dimensions: centralization, reporting lines, curricular authority, position classification, and others. Where designers are situated within an organizational structure can enhance or inhibit their ability to lead online learning initiatives and build influence with faculty and administrators (Tran \& Tian, 2013). However, little research has been conducted on the influence of these structures and dimensions on instructional designers and their ability to lead online learning initiatives. This qualitative, comparative case study examined the influence of organizational structures on the empowerment and leadership opportunities of instructional designers in higher education to determine which organizational structures most positively influenced instructional design leadership for online learning initiatives.

\section{Literature Review}

Universities and university systems are complex organizations with many distinct and interconnected systems and structures. This study focused on the influence of these complex structures and systems and their influence over leadership and empowerment of instructional design teams. As such, the study was framed through systems theory, which offers "conceptual and methodological alternatives for studying and understanding how organizational systems function" (Patton, 2015, p. 139). University systems and structures vary based on many attributes. High-level structural elements include public or private funding, for-profit or nonprofit status, stand-alone campuses, or multi-campus systems, and unionized or nonunionized faculty bodies. Pennisi (2012) indicated that organizational structure elements, which determine the power distribution and decision-making authority in organizations, also influence organizational mission, vision, goal-setting, and strategic plans - critical leadership functions. The structural attributes addressed specifically in this study include leadership, academic or administrative reporting lines; curricular authority and management of online programs; and centralization or decentralization of instructional design teams and resources. 


\section{Leadership in Higher Education}

Universities have many embedded leadership structures, such as a blend of both centralized and decentralized decision-making authority. As a result, leadership in higher education may take different forms based on the individual university, or even between distinct units in a single organization. As online learning has become a standard element of the culture of most universities, leadership approaches have changed to accommodate the different needs of a distributed organization (Nworie, 2012). Three key leadership theories have shaped the approach that universities take for online learning and instructional design: transformational leadership, authentic leadership, and shared leadership.

Transformational leaders are grounded in "the assumption that the actions of leaders are based on moral, ethical, and equitable consideration of everyone within an organization" (Nworie, 2012, p. 4). Transformational leaders are further characterized by their ability to enact positive change through collaboration and influence. In higher education, such collaboration is a necessity; decision-making authority often rests with faculty, but online learning initiatives involve administrators, faculty, and staff alike. Black (2015) described transformational leadership as an increasingly common leadership structure in higher education due to the emergence of online learning. In this paradigm, leaders act as change agents through relationship-building and experience with their institution's structure and culture, rather than through transactional means (Black, 2015). Fredericksen (2017) suggested that in higher education, "the online learning leader must demonstrate a collaborative approach. There must be an embrace of a transformational leadership style where the leader inspires change - a mandate or directive will not work" (p. 4). Transformational leadership is a necessary leadership approach in higher education online learning due to the distributed power and authority inherent in university organizational structures.

Authentic leadership expanded on the foundations of transformational leadership to focus on leading through trust, transparency, honesty, and consistent decision-making (George, 2003, 2010; George et al., 2007; Kiersch \& Byrne, 2015). Authentic leaders also focus on changing organizational practices but integrate care for the well-being of individuals and teams as a core tenant of their approach. Opatokun et al. (2013) discovered four key predictors that pointed toward authentic leadership among higher education administrators: self-awareness, balanced processing of information, an internalized moral perspective, and relational transparency (p. 61). Self-awareness was the highest predictor of authentic leadership, but all four dimensions were positive predictors (Opatokun et al., 2013). Authentic leaders are transparent and open communicators; they work to develop sustainable cultures of openness to change and innovation (Baer et al., 2015). Given the significant change in higher education through online learning, an authentic, collaborative approach is critical for effective change leadership.

Both transformational leadership and authentic leadership have important implications for higher education instructional designer teams. While both emphasize the importance of transparency and collaboration in decision-making toward positive change, some organizational structures restrict opportunities for such collaboration when the formal means of decisionmaking excludes or deemphasizes the influence of specific groups. Shared leadership theory plays a critical role in bifurcated organizational structures, serving as the basis for leadership functions where vertical administrative leadership converges with faculty governance (Ciabocchi et al., 2016). While a culture of shared leadership is critical to the success of online learning initiatives, the involvement and influence of instructional design teams in these leadership 
structures depends heavily on their location within the university. However, instructional design teams are inconsistently organized within these decentralized, bifurcated leadership structures; some design teams are in academic departments, while others are in administrative departments. Instructional Designer Roles and Reporting Lines

Instructional designers have identified themselves as working within IT departments, continuing education departments, and academic affairs, as well as in centers for teaching and learning, dedicated online learning teams, and university libraries (Intentional Futures, 2016). The roles of these instructional designers vary from team to team, although there are several key attributes that most instructional designers associate with their roles and work such as course design, course development, technology training, pedagogy, and teaching. Kumar and Ritzhaupt (2017) interviewed eight instructional designers to further clarify their roles and responsibilities. These designers perceived faculty as their main audience, and that the work of instructional designers was primarily in partnership with faculty.

While there has been significant debate about the role of higher education instructional designers, many institutions have clearly defined these roles. Brigance (2011) suggested that instructional designers are primarily collaborators and leaders in online course design, partnering with faculty to design their courses as experts in pedagogy, community building, instructional technology, creating learning experiences, and synthesizing those elements into a cohesive course. Brigance (2011) further suggested that instructional designers should act as faculty collaborators rather than support staff, as their expertise in design, development, and the program lifecycle positions them well to lead and collaborate in these areas. Shaw (2012) expanded on this view of instructional designers as leaders by aligning the work of instructional design with leadership functions in higher education. Shaw (2012) listed key leadership functions such as casting a vision, establishing strategic priorities, and developing organizational trust as the core work of higher education instructional design within the context of online learning.

Although instructional designers are equipped to lead through their unique expertise, they may not be positioned to lead. A report from Intentional Futures (2016) identified key barriers that designers face in their work. Three of these key barriers were lack of faculty buy-in, limited time and resources, and challenges with institutional leadership and initiatives. The report also noted that the structures needed to empower and amplify instructional design teams were not in place, both in broader strategic initiatives and for ownership in their own work. For universities to advance online initiatives through the leadership and expertise of instructional designers, these barriers must be considered through the lens of organizational structure.

Instructional design teams are organized inconsistently between academic and administrative lines. Faculty shared governance is the primary structure for academic reporting lines at most universities. Shared governance is intended as a means of protecting faculty from external and internal influences on what and how they choose to research and teach, commonly known as academic freedom (Eastman \& Boyles, 2015). This layer of structural protection and associated practices have positioned faculty and administrator relationships as adversarial, resulting in conflict over administrative interests such as enrollment targets, and faculty interests, such as innovative teaching practices (Eastman \& Boyles, 2015). As non-faculty educators, instructional design teams that are structured under academic reporting lines do not typically qualify to participate in faculty governance, even as their work and roles are heavily influenced by these structures.

Teams with administrative reporting lines are organized through vertical structures (Ciobocchi at al., 2016). Vertical structures are characterized by hierarchical leadership, with 
decision-making power held by those with positional authority. Instructional design teams in administrative reporting lines are commonly organized under departments of information technology, human resources, or under dedicated departments for online learning and technology. Del Favero and Bray (2005) noted that the widely divergent cultures and structures between faculty and administrators are the key reasons for conflict between the two groups. Administrators focus on systems-level initiatives, or decisions that have an impact on the entire organization, while faculty focus more on individual motivations such as research funding, teaching, and service to the department. This difference in scope does not suggest selfish motivations for one group or the other, but that there is a significant difference in perspective and the nature of the work between faculty and administrators, and both have great value for the organization. Instructional designers, however, work at the convergence of these two cultures and perspectives. They work closely with faculty in the design and development of online courses, and with administrators in the strategic work of advancing online learning across their institutions. This convergence of perspectives - both faculty and administrator - equips instructional designers to effectively lead online learning initiatives. However, there is again variance in the structures for the organization and management of online programs, affecting the scope of roles and authority instructional designers may have in online learning initiatives. Curricular Authority and Management of Online Programs

Legon and Garrett (2017) explored the overarching structures for program delivery and management of online programs as identified by university chief online officers. They discovered that $71 \%$ of four-year institutions structured their online program management through independent academic units, while $21 \%$ centralized online program management through dedicated online learning teams, such as a global or online campus. They also discovered that four-year private institutions leaned toward institutional ownership of curricula, while public four-year institutions varied. Twenty-nine percent of these participants indicated institutional ownership of the curricula, $21 \%$ indicated shared ownership between the institution and the individual faculty, and $21 \%$ indicated "case-by-case institutional licensing" of the curricula (p. 30). Paulucci and Gambescia (2007) categorized 239 universities between internal or external structures for managing online programs, with the internal category including resources housed within academic units or centralized teams, while the external category focused on vendor outsourcing or partnerships with other universities, such as consortia. The majority of institutions-90\% - used exclusively internal structures for online program management; 62\% indicated resources were housed by academic units (Paulucci \& Gambescia, 2007).

Andrade (2016) explored similar structures, focusing on the centralization or decentralization of online learning resources within institutions. Andrade (2016) identified key advantages to a centralized online program management structure, including the centralization of instructional designers: consistency, quality, and cost-effective development of online courses. Andrade also indicated that administrators preferred a centralized structure. The decentralized structure focused on departmental control and management of online programs; Andrade noted one significant disadvantage to a decentralized structure: focusing efforts away from institutionwide efforts, which are often more cost-effective and encourage broader adoption. Online program management happened more commonly through internal resources than through external vendor or consortia relationships; it also happened more commonly through a decentralized structure, where individual academic units manage their own online courses and curricula. However, the influence of these structural dimensions for online program management 
on instructional design leadership have not been explored, including the focus on centralization or decentralization of instructional design teams.

\section{Centralization or Decentralization of Instructional Design Teams}

Reid (2018) indicated that instructional designers in higher education may work within centralized, decentralized, or blended - both centralized and decentralized - structures. According to a study by Fong et al. (2017), nearly half of surveyed instructional designers operated in a centralized organizational structure, while $25 \%$ of the respondents indicated that their teams existed as a service within a single academic unit. The researchers also associated the higher rate of centralization with the technical nature of instructional design, aligning the field closely with information technology services to reduce duplication of effort and save costs. However, the work of instructional design is more pedagogical than technical. The researcher's data supported this assertion: two of the highest listed services offered by instructional designers — course design and training for online pedagogy — are not technical in nature, but pedagogical. Additionally, the researchers did not indicate whether the designers who indicated a centralized structure were aligned under academic or administrative reporting lines; without this information, it is unknown from the study if instructional designers were organized closely with IT, other administrative departments, or through academic reporting departments.

\section{Research Questions}

The literature review focused on four main dimensions of organizational structure: leadership, academic or administrative reporting lines, management of online programs, and centralization or decentralization of instruction design teams. Although research existed in each structural dimension, no literature could be found on the convergence of these dimensions and their influence on the empowerment and leadership opportunities for higher education instructional design teams. Additionally, the research did not reveal any specific recommendations for structuring instructional design teams for effective leadership in online learning initiatives. As such, this research study addressed the identified gap in the literature through the following research question and sub questions:

1. How do organizational structures in a university or college setting most positively influence the ability of instructional designers to lead online learning initiatives in higher education?

a. What are the organizational structures in place at colleges and universities for instructional designers?

b. How do instructional designers in varied higher education organizational structures participate in the design, redesign, and evaluation of university courses and programs?

c. How do faculty and administrators empower or disempower instructional designers when collaborating on online learning initiatives?

\section{Methods}

A qualitative research paradigm was chosen for this study as the best fit to answer the research question and sub questions. The literature warranted a deeper analysis of the experiences of instructional designers, faculty, and administrators within different organizational structures, as well as an evaluation of their respective institutional contexts through a systems theory framework (Merriam \& Tisdell, 2016). Although many case studies focus on a single 
case, this study called for multiple cases to compare the experiences of instructional designers, faculty, and administrators in a subset of common organizational structures - specifically, universities with instructional design team structured differently in each organization. Three public research universities were selected for the comparative case analysis.

\section{Population and Sampling Method}

The population for this study consisted of four-year universities in the United States. Case participants for this study met a short list of criteria to ensure that the research questions could be adequately addressed. First, they were all public, nonprofit institutions with physical campuses and a sizable online presence. Next, the participating universities had a Carnegie classification of at least Doctoral Universities: Moderate Research. Finally, they must have offered at least one fully online graduate degree.

This study warranted a multi-case sampling method to find participants from multiple case sites. Purposive sampling was used to identify specific organizations and participants, ensuring that the data collected was relevant to the research questions (Saldaña \& Omasta, 2017). Specifically, purposive sampling was guided by specific sampling criteria for both the organizations and individuals involved in the study. The sampling criteria for case sites were the criteria listed in the population; additionally, selected sites had to have a team of instructional designers and had to fit one of the three organizational structures to be evaluated in this study: a centralized design team with academic reporting lines and distributed curricular authority, a centralized design team with administrative reporting lines and distributed curricular authority, or a decentralized or blended design team with either academic or administrative reporting lines and distributed curricular authority. All three selected case sites had structures with distributed curricular authority.

Approximately 50 institutions were assessed through their public-facing websites to ascertain their compatibility with the scope of the study. After selecting and confirming three case sites which had met the sampling criteria for the study, participants for the semi-structured interviews were identified at each university. Participants consisted of individuals with one of three distinct roles: instructional designer, online faculty member, or online learning administrator. Up to three individuals in each role type were contacted at each participating case site; Semi-structured interviews were conducted with all individuals who agreed to participate, with four participants from the first university, three from the second, and three from the final institution. The three participating institutions and their organizational structures are listed in Table 1; pseudonyms were used for each institution.

\section{Table 1}

Institution Names and their Organizational Structures

\begin{tabular}{ll}
\hline Institution Name (Pseudonym) & Organizational Structure \\
\hline Southeast Public University & $\begin{array}{l}\text { Academic reporting lines with a centralized instructional } \\
\text { design team }\end{array}$ \\
\hline Great Plains Public University & $\begin{array}{l}\text { Administrative reporting lines with a centralized instructional design } \\
\text { team }\end{array}$ \\
\hline Midwest Public University & $\begin{array}{l}\text { Academic reporting lines with a blended (centralized/decentralized) } \\
\text { instructional design team }\end{array}$
\end{tabular}

\section{Research Instruments}


Three semi-structured interview protocols were developed-one for each role type. The protocols were field-tested by a focus group of subject matter experts who provided feedback on each question to ensure relevance and validity of the instrument. Interview protocols for each role type may be found in Appendices A, B, and C. Interviews were conducted remotely through Zoom; all interviews were recorded, transcribed, and de-identified to ensure anonymity for all participants.

\section{Data Collection and Analysis}

Data collection consisted of a series of semi-structured interviews, 60-90 minutes in length, with instructional designers, online faculty, and online learning administrators from each participating university. Interview questions were developed based on the research question and sub questions, including the following topics: (a) online learning initiatives; (b) organizational structure of the instructional design team; (c) leadership approaches; (d) quality of working relationships between university faculty and staff; (e) program and course design practices; and (f) decision-making processes. These interviews comprised the majority of data collection for the study. Documents relevant to the study, including course syllabi, departmental processes, organizational charts, course design documentation, campus and departmental policies, and university websites, were collected for analysis (Saldaña \& Omasta, 2017). Documents used were either publicly accessible or were provided by interview participants for each institution. Data collection took place over a total duration of three months. The ten semi-structured interviews were transcribed verbatim, de-identified, and coded through three a priori and emergent passes in process, values, and causation codes (Saldaña \& Omasta, 2017). Three additional experts in the field assessed the coding manual, coded transcripts, and themes for triangulation of the data.

\section{Trustworthiness and Ethical Considerations}

To ensure the credibility and trustworthiness of the study, I selected well-established methods and a plan for confirming the validity of all instruments used to collect data (Shenton, 2004). Additionally, I became familiar with the culture of each case site, working to prevent prolonged engagement to ensure no bias was introduced to the study (Shenton, 2004). To support transferability of findings, I ensured that all boundaries were clearly articulated so that readers of the research could make informed judgments on transferability to other situations and contexts (Shenton, 2004). I ensured that replication of the study would result in similar, dependable findings through the careful description of the research design, process, and practices for data collection and analysis (Shenton, 2004). Finally, to ensure confirmability, I chose multiple data collection methods for triangulation, both with individual case sites and for the comparative analysis of the data (Shenton, 2004).

This study was approved by the university's institutional review board (IRB). I followed each case site's procedures for institutional review; each case site deferred to the home institution's IRB approval for the study. All participants received full disclosure of the purpose, methods, and process for all data collected, and I received informed consent from every participant prior to data collection.

\section{Limitations}

Although instructional designers are commonly employed by institutions of higher education, they do not all share the same roles and responsibilities. Many instructional designers operate as faculty technology support, while others act as collaborators in the design of academic courses and programs. Others yet may be primarily academic technologists with instructional designer titles. These differences in role definition may have influenced the scope and case 
selection for the study. Further, case site conditions, such as leadership transitions or financial hardship, may have influenced the study.

This study focused on research universities in the United States; the case selection was guided by this criterion, and was intended to provide a focused, intentional perspective on the ways organizational structures influence instructional designers in a large subset of United States higher education institutions. Additionally, the study addressed specific role types in higher education, notably those with a focus in online learning. The study may have relevance for traditional university settings, but they were not a direct part of this study. Finally, data collection was conducted at a distance through a video conferencing tool.

\section{Results}

The results of this study will be described in four sections: one each for the three cases for an overview and situational context, and one final section for the comparative analysis results and themes.

\section{Southeast Public University}

Southeast Public University (pseudonym) is a public research institution located in the southeastern United States with an enrollment of more than 67,000 students. Southeast Public University has a fully online virtual campus with more than 80 available degrees and certificates and is accredited by the Southern Association of Colleges and Schools Commission on Colleges (SACSOC). The institution is respected as a hub of innovation and research in instructional design, blended learning, and online learning. Southeast Public University met the first structure profile for the study: centralized instructional design team with academic reporting lines and distributed curricular authority.

Southeast Public University has a digital learning division comprised of 150 staff. It is led by a vice provost of digital learning with direct reporting lines to the university provost. Its six separate teams oversee initiatives including media development, classroom technology, mobile learning, and an innovation lab. The largest team, the Online Learning Center, acts as the central hub of online learning activity and expertise, and houses the instructional design team.

The instructional design team is comprised of a director, three team leaders, and 20 fulltime, faculty rank instructional designers. Each team lead oversees an area of focus within the field of instructional design: course design, adaptive learning, or strategic initiatives; the director of the team also oversees separate teams on technical support and LMS administration. The instructional design team primarily facilitates the design and development of online courses through consultative practices with faculty and by providing ongoing faculty professional development. Instructional designers at Southeast Public University are unionized faculty members and are subject to the university's collective bargaining agreement, with workload percentages as follows: 85\% course design and faculty development, 10\% scholarly research, and $5 \%$ service to the university.

Four individuals (pseudonyms used) were interviewed at Southeast Public University: Julia, an instructional designer from the course design sub-team; Mike, an online nursing faculty and program director; Brian, the executive director of the Online Learning Center; and Demitri, the vice provost for digital learning. All interviewees indicated that the organizational structure at their institution contributed to their individual success, as well as to the success of their teams and the institution itself. The Online Learning Center had broad support from across the institution, a perception the participants indicated was earned through consistent expertise and evidence of effectiveness. One participant, Demitri, indicated that the digital learning division 
was seen as "a solution to problems or a toolset for accomplishing objectives" due to its academic reporting lines: “...it's framed as a fundamentally academically serving enterprise, not a technology function."

\section{Figure 1}

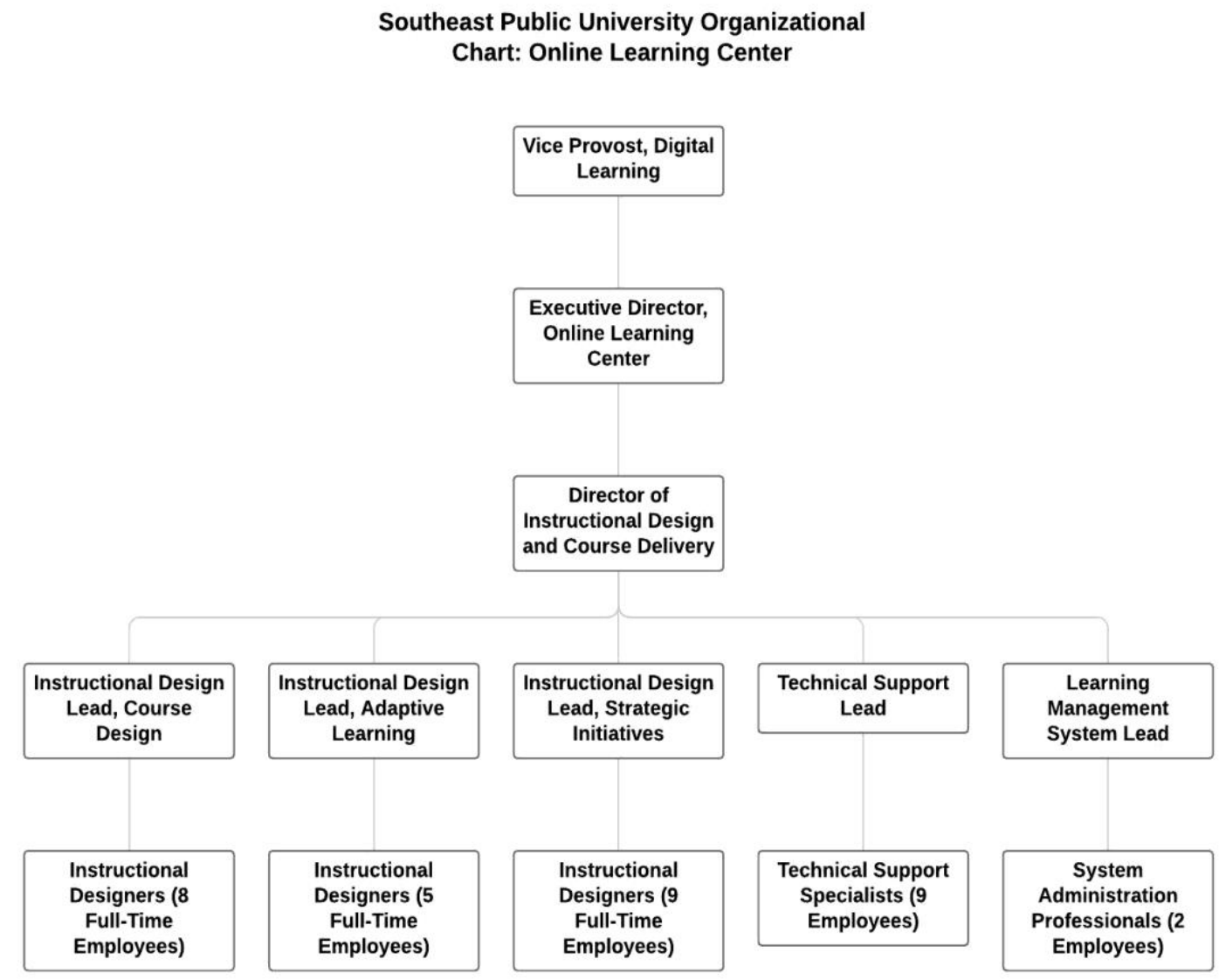

Organizational Chart of the Southeast Public University Instructional Design Team

When asked about the clarity of roles for instructional designers and online learning administrators, the participants indicated that the roles were clearly defined, and that the centralized organizational structure strengthened role clarity. Both Mike, the faculty participant, and Demitri, vice provost for digital learning, indicated that a balance of authority between faculty and administration was positive, and that the university empowered both groups in their related but distinct areas of focus. Julia, the instructional designer participant, noted her faculty status as an important part of her success, as well as the advancement opportunities it afforded.

Julia also emphasized that she was empowered in her work by the online learning administrators, as evidenced by the separate technology support teams and a focus on partnering with faculty in course design. However, Brian and Julia both noted that even though instructional designers were respected and valued, they still experienced significant role misperception and 
resulting disempowerment. According to Brian, "a lot of faculty [members] don't really understand what an instructional designer is."

At Southeast Public University, the instructional design team is centralized under academic report lines and faculty retain curricular authority. Instructional designers hold formal faculty appointments and see this as empowering and situating them as equal collaborators with teaching faculty, but still experience misperception of their roles as experts in online pedagogy and course design. Finally, Brian, the executive director of the Online Learning Center, had previous experience as an instructional designer in higher education, which he and Julia expressed contributed to his high effectiveness as a leader for instructional designers.

\section{Great Plains Public University}

Great Plains Public University (pseudonym), a public research institution in the Great Plains region of the United States, is a university within the Great Plains System, a state-funded office that led public education institutions across its state of origin. With an enrollment of approximately 16,000 students, Great Plains offers 16 degree programs and 11 certificates fully online and is accredited by the Higher Learning Commission (HLC). Great Plains does not hold any distinctions of excellence in instructional design from outside organizations, although its faculty and designers participate in scholarly research and conferences around online learning.

The instructional design team at Great Plains Public University is housed in the Office of Digital Learning, which is led by a director of digital learning, who has a dual reporting structure through information technology (IT) and academic affairs. The team consists of two instructional designers, an instructional technologist, an open education resources (OER) librarian, and a student recruiter for online programs. Great Plains Public University met the second structure profile for the study: a fully centralized online learning team with an administrative reporting structure and distributed curricular authority. 
A Multi-Case Study of Instructional Design Teams

\section{Figure 2}

Organizational Chart of the Great Plains Public University Office of Digital Learning

Great Plains Public University Organizational

Chart: Office of Digital Learning

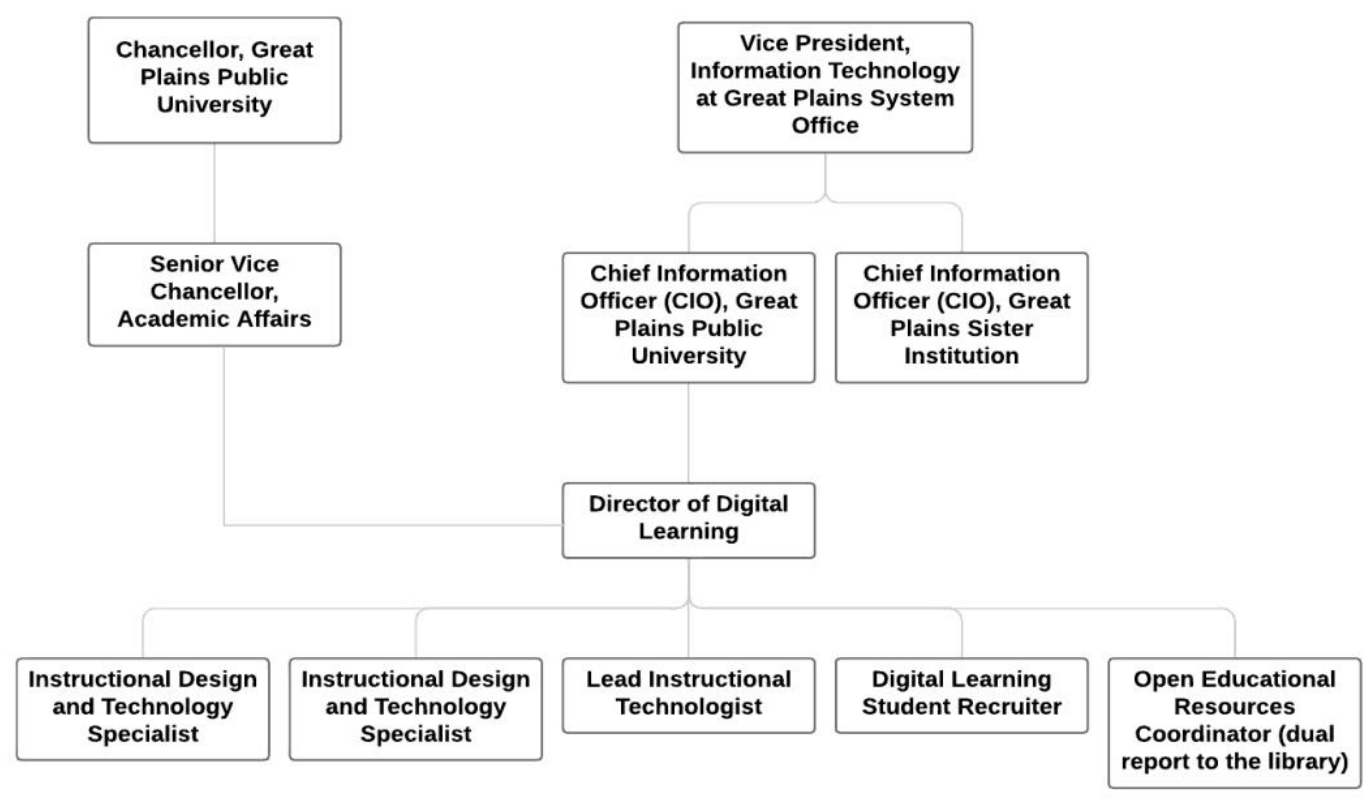


The Office of Digital Learning is structured under the Office of Information Technology and has no direct reporting lines to academic affairs other than through its director. Instructional designers on the team have a wide range of responsibilities including trainings, LMS support, and course design. Course design workload is determined based on faculty interest on a firstcome, first-serve basis. The faculty at Great Plains Public University are unionized; the instructional designers do not hold faculty titles or appointments. Three professionals (pseudonyms used) were interviewed: Dora, an instructional designer; Anna, a faculty member in library science and a funded faculty liaison to the Office of Digital Learning; and Carla, the Director of Digital Learning.

Each participant indicated a different perspective on the value of Great Plains Public University's organizational structure. Carla favored the administrative reporting lines but shared that she is often over-affiliated with information technology. Carla indicated that the territorial nature of academic decision-making made it very difficult to work with faculty in instructional design, in part due to their reporting through administrative lines and resistance to a centralized structure. Dora, the instructional designer participant, was favorable to both centralization and the alignment with IT, and similar to Carla favored it for the technology-centric areas of their roles, which comprised the majority of their workload. Anna, the faculty participant, indicated that the decentralized nature of academic units made it challenging to systematize decisions and resources, and suggested that the centralized nature of the Office of Digital Learning was positive as a potential solution to improve connected decision-making. However, Anna also noted that many faculty members, including herself, were not aware of the organizational structure, or that the Office of Digital Learning was structured under IT.

Ambiguity around the organizational structure also extended to faculty perceptions of the roles of the instructional designers; Dora disclosed that she did not know the scope of her director's role, and that her own role was "about as fuzzy as you can get. There's a whole lot of 'other duties as assigned." Anna and Carla echoed the role ambiguity, with both participants confirming that a lack of communication and visibility made it difficult for faculty to understand what instructional designers could do, which both indicated was much more than the technology support for which they were most contacted. Further, Carla noted the classist behaviors of many faculty members and the negative power structure of their decentralized faculty: "they can dismiss us, and not have any love lost." Carla further shared that classist faculty behavior frequently characterized the relationships between faculty and her team. The hierarchical structure placed faculty above staff, exacerbating the lack of empowerment, visibility, and role clarity for the instructional designers.

Midwest Public University

Midwest Public University (pseudonym) is a public research institution located in the Midwest region of the United States. With an enrollment of approximately 27,500 students across six campuses, Midwest Public University has 30 fully online degree programs and certificates, with 850 courses offered fully online. Midwest Public University is accredited by HLC and is nationally and internationally respected for its excellence in research for distance education and technology through a funded online learning research center. The institution is a part of the Midwest System of Universities which operates under a single Board of Regents. Midwest Public University met the third structure profile for the study: blended (centralized and decentralized) instructional design teams with academic reporting lines and distributed curricular authority. 
The centralized instructional design team at Midwest Public University, known as the Center for Teaching and Learning (CTL), is organized with a flat, non-hierarchical structure, where all employees report to the Director of the Center for Teaching and Learning. The CTL has academic reporting lines up through the provost, and consists of three instructional designers, an organizational development consultant, an LMS administrator, and two learning technologists. The CTL went through a reorganization in 2014 that merged the team focused on face-to-face learning with the team focused on online learning.

\section{Figure 3}

Organizational Chart of the Midwest Public University Center for Teaching \& Learning

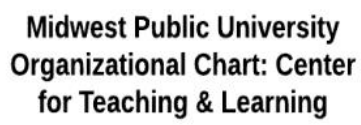

Teaching, Learning, and Technology Consultant

Senior Consultant for Organizational Development

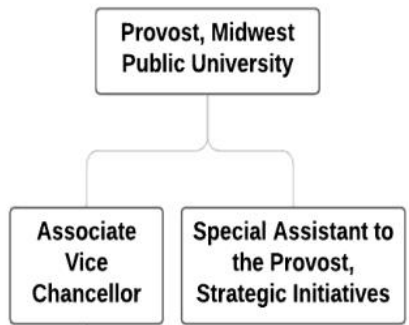

Midwest Public University has a blended structure for its instructional design teams; the CTL is the centralized team, but individual academic units may also house instructional designers, such as the School of Education, which has a single instructional design professional among 150 faculty and staff.

Instructional designers from the CTL focus primarily on consultation with faculty members who teach in any modality, with consultations primarily focused on pedagogy and teaching practice. All instructional designers from the CTL must hold terminal degrees and significant teaching experience, but no formal education in instructional design is required. The decentralized instructional designer from the School of Education focused on both technology and pedagogy, and on school-wide initiatives such as assessment practices and accessibility. However, due to the partially decentralized structure of instructional designers at Midwest Public University, the School of Education may define the role of its instructional designer differently than other academic units. There is no uniform or consistent role clarity for the decentralized 
instructional designers at Midwest Public University. Three individuals (pseudonyms used) were interviewed: Sid, the decentralized instructional designer from the School of Education; Alex, the centralized instructional designer; and Nina, a faculty member and special assistant to the provost focused on new online programs and associated services.

According to all participants, there were significant challenges with the blended organizational structure. Alex noted a gap in leadership due to the CTL's flat structure and limited management, with resulting challenges of scope and role clarity. Nina celebrated the effectiveness of the CTL but indicated that the structure was also due to budget constraints limited resources. Sid noted feeling isolated in his academic unit and disconnected from the centralized team. Although Alex indicated that instructional designers in the CTL had roles with a clear focus on consulting with faculty, Sid experienced signification role misperception due to his isolation within a single academic unit.

\section{Figure 4}

Organizational Chart of the Midwest Public University School

Midwest Public University School

of Education Organizational Chart

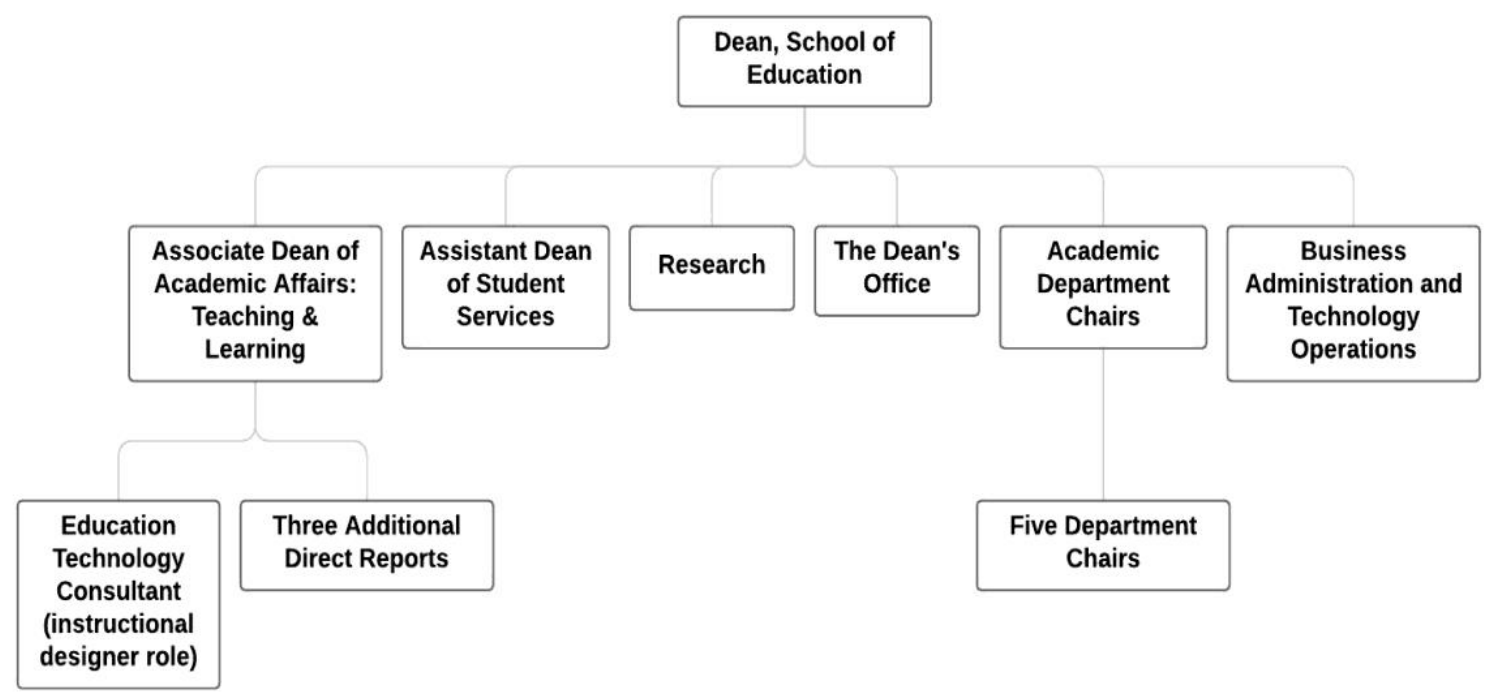


Faculty members described him as a "tech guy,", rather than an expert in online pedagogy and course design, which he indicated as areas of expertise. Sid also struggled with negative relationships with faculty who actively disempowered him and did not see him as a collaborator due to his non-faculty status. Sid also noted that instructional design at the School of Education was severely understaffed; as the sole person responsible for instructional design and technology, he had no advocates to help clarify and focus his work on projects more closely aligned with the work of instructional design. Instead, Sid often worked as faculty technical support, out of convenience for faculty who did not want to use the centralized universities services.

Overall, the centralized instructional design team at Midwest Public University was empowered to lead and work in collaboration with faculty, but the decentralized instructional designer experienced severe role misperception and negative relationships due to understaffing and bias against his non-faculty status. The blended organizational structure indicated disempowerment and poor leadership opportunities for the decentralized instructional designer, but not for the centralized instructional design team.

\section{Comparative Case Analysis}

The research questions for this study focused on discovering which organizational structure most positively influenced instructional design leadership over online learning initiatives, including instructional designer roles and empowerment. The comparative case analysis revealed several important results. First, organizational structure strongly affected the role perception, professional advocacy, empowerment, and leadership opportunities for instructional designers. Centralized instructional designers at each case site had more opportunities for leadership and advocacy than the decentralized instructional designer, who had no advocacy, felt isolated and disempowered, and had very few opportunities for leadership. Centralized instructional designers still experienced challenges with role misperception with university faculty; however, participants in centralized structures indicated that centralization enabled clearer role definitions and empowerment to pursue the primary work of instructional design: expertise in pedagogy and course design. The decentralized designer, in contrast, struggled to gain time or empowerment to pursue pedagogical work, noting that faculty often expected his support for simple technology tasks that were not suited to his role, valuing convenience more than his considerable expertise.

The instructional designers in academic reporting structures experienced more positive role perception, while those in administrative structures were severely limited in their ability to pursue pedagogical work. The roles of designers in centralized, academic reporting structures were more oriented toward course design, faculty professional development, pedagogy consulting, and broad initiatives that impacted the entire institution. Designers in administrative structures, however, noted an over-association with information technology and challenges with role clarity due to the expectation of their work being focused on technology.

The comparative analysis also revealed the value of positional parity between faculty and instructional designers. At Southeast Public University, where instructional designers held faculty appointments, designers had a clear scope for their role, broad recognition and respect from faculty, and administrators who both understood and advocated for their work in course design and pedagogy. In contrast, the decentralized instructional designer and designers organized in administrative structures experienced negative relationships, a toxic work environment, faculty classism, and pressure to focus on technology support instead of pedagogy and course design. 
All participants noted the struggles of scale within instructional design and the importance of having online learning leaders experienced with instructional design practice in higher education. Issues of scale negatively impacted all participants, specifically their ability to lead online learning initiatives with institution-wide impact. Without enough staff to meet the demand for technology support and course design collaborations, instructional designers were far less likely to pursue systems level change initiatives for online learning.

\section{Discussion}

This study sought to uncover the most effective organizational structure for instructional designer leadership and empowerment in higher education institutions. The data analysis revealed that the structure which most positively influenced instructional design leadership over online learning initiatives was a centralized instructional design team with academic reporting lines. Designers in this structure had clearer role definitions, were empowered by their online learning administrators to pursue pedagogical work, had largely positive relationships with faculty, and experienced the professional advocacy necessary for them to lead online learning initiatives. Centralized instructional designers had more opportunities for leadership, while the decentralized instructional designer experienced disempowerment and limited collaboration with faculty.

Instructional designers in academic reporting structures were more closely aligned with faculty in the design of online courses; instructional designers in administrative reporting structures were often over-aligned with their technology skills, resulting in their pedagogical expertise being undervalued. Additionally, the findings indicated the importance of addressing issues of scale for instructional design teams; teams that are understaffed are less likely to lead online learning initiatives. Decentralized instructional designers and those in administrative reporting structures were far more likely to experience role misperception from faculty and to have their work as pedagogy experts undervalued in favor of providing convenient technology support for faculty. Finally, the comparative results indicated the significant value of online learning administrators having direct experience as instructional designers to effectively advocate and empower their instructional design teams to lead.

\section{Recommendations and Conclusions}

Given the results of this study, it is recommended that institutions that are restructuring or building new instructional design teams implement centralized structures with academic reporting lines for their teams. The benefits of both centralization and academic reporting lines are clear: better advocacy and empowerment, better alignment with the pedagogical work of both designers and faculty, and less role misperception for instructional designers. Structuring these teams toward empowerment and better definitions of their roles as pedagogy experts may help them sustain their leadership on the initiatives they led, to great effect, during the COVID-19 pandemic. This study also revealed the importance of three additional structural elements: appropriate instructional design staffing for the size and scale of the institution, leadership experience with instructional design, and positional parity with faculty.

Challenges of scale with instructional design are unlikely to be resolved simply by centralizing instructional design teams. Understaffed teams are often unable to lead initiatives because they are oversaturated with other priorities - even more so when the designers are also serving as technology support. As such, it is also recommended to increase the size of instructional design teams to be realistic for the size and scope of the institution's online learning presence, and to reduce the responsibilities of technology support from the instructional designer 
role, ideally through a team of dedicated instructional technologists and support specialists. Individuals who lead instructional design teams should be experienced with the work of instructional design to maintain boundaries of responsibility that empower instructional designers to lead online learning initiatives. Leaders who have no experience as instructional designers themselves may struggle to adequately lead instructional design teams. As such, it is critical for the advancement of online learning for instructional designers to gain leadership experience and for institutions to hire and promote instructional designers into formal leadership roles with positional authority.

Based on this study, instructional designers should have positional parity with faculty to generate the shared respect and value necessary for the collaborative work of instructional design and leadership in online learning initiatives. Positional parity does not necessarily mean that all instructional designers need faculty appointments. Parity can be achieved through other means as well, such as shared leadership in academic program design, advancement pathways for instructional designers that mirror the promotion and tenure cycle and normalizing an institutional culture that equally values the contributions and perspectives of both staff and faculty. Finally, for institutions that have a decentralized or blended organizational structure for their instructional designers, it is strongly recommended to implement changes that protect and improve the working conditions, empowerment, effectiveness, and opportunities for leadership for instructional designers.

Instructional designers, in any structure, are a mission-critical resource for institutions of higher education. It is paramount to empower, equip, and position them to lead their organizations alongside faculty into the future of online learning through their unique and valuable expertise. Organizational structures have a significant influence on the empowerment and leadership of instructional designers; intentionality and a well-chosen structure can position our institutions for the right kind of effective leadership as we move further into the digital age. 


\section{References}

Allen, I. E., \& Seaman, J. (2016). Online report card: Tracking online education in the united states. Babson Research Group.

Andrade, M. S. (2016). Effective organizational structures and processes: Addressing issues of change. New Directions for Higher Education, 173, 31-42. https://doi.org/10.1002/he.20177

Baer, L. L., Duin, A. H., \& Bushway, D. (2015). Change agent leadership. Planning for Higher Educational Journal, 43(3), 1-11. https://www.scup.org/page/phe

Beirne, E., \& Romanoski, M. O. (2018). Instructional design in higher education: Defining an evolving field [White paper]. OLC Research Center for Digital Learning \& Leadership. https://olc-wordpress-assets.s3.amazonaws.com/uploads/2018/07/Instructional-Design-inHigher-Education-Defining-an-Evolving-Field.pdf

Black, S. A. (2015). Qualities of effective leadership in higher education. Open Journal of Leadership, 4, 54-66. https://doi.org/10.4236/ojl.2015.42006

Brigance, S. (2011). Leadership in online learning in higher education: Why instructional designers for online learning should lead the way. Performance Improvement, 50(10), 43-48. https://doi.org/10.1002/pfi.20262

Ciabocchi, E., Ginsberg, A., \& Picciano, A. G. (2016). A study of faculty governance leaders' perception of online and blended learning. Online Learning, 20(3), 52-73. https://doi.org/10.24059/olj.v20i3.974

Del Favero, M., \& Bray, N. (2005). The faculty-administrator relationship: Partners in prospective governance? Scholar-Practitioner Quarterly, 3(1), 53-72.

https://www.learntechlib.org/j/ISSN-1540-9392/

Eastman, N. J., \& Boyles, D. (2015). In defense of academic freedom and faculty governance: John Dewey, the 100th anniversary of the AAUP, and the threat of corporatization. Education and Culture, 31(1), 17-43. https://doi.org/10.1353/eac.2015.0005

Fong, J., Uranis, J., Edward, M., Funk, C., Magruder, E., \& Thurston, T. (2017). Instructional design and technology teams: Work experience and professional development. UPCEA. http://upcea.edu/IDResearch

Fredericksen, E. E. (2017). A national study of online learning leaders in US higher education. Online Learning, 21(2). https://doi.org/10.24059/olj.v21i2.1164

George, B. (2003). Authentic leadership: Rediscovering the secrets to creating lasting value. Wiley.

George, B. (2010). True north: Discover your authentic leadership (Vol. 143). Wiley. 
George, B., Sims, P., McLean, A. N., \& Mayer, D. (2007). Discovering your authentic leadership. Harvard Business Review, 85(2), 129-140. https://hbr.org

Hodges, C., Moore, S., Lockee, B., Trust, T., \& Bond, A. (2020). The difference between emergency remote teaching and online learning. Educause Review. https://er.educause.edu/articles/2020/3/the-difference-between-emergency-remote-teaching-andonline-learning

Intentional Futures (2016). Instructional design in higher education: A report on the role, workflow, and experience of instructional designers [White paper]. https://intentionalfutures.com/insights/portfolio/instructional-design/

Kiersch, C. E. \& Byrne, Z. S. (2015). Is being authentic being fair? Multilevel examination of authentic leadership, justice, and employee outcomes. Journal of Leadership \& Organizational Studies, 22(3), 292-303. https://doi.org/10.1177/1548051815570035

Kumar, S., \& Ritzhaupt, A. (2017). What do instructional designers in higher education really do? International Journal on E-Learning, 16(4), 371-393. https://www.aace.org/pubs/ijel/

Legon, R., \& Garrett, R. (2017). The changing landscape of online education (CHLOE): Quality Matters \& Eduventures survey of chief online officers. Eduventures.

https://www.qualitymatters.org/sites/default/files/research-docs-pdfs/CHLOE-First-SurveyReport.pdf

Merriam, S. B., \& Tisdell, E. (2016). Qualitative research: A guide to design and implementation (4th ed.). Jossey-Bass.

Nworie, J. (2012). Applying leadership theories to distance education leadership. Online Journal of Distance Learning Administration, 15(5), 1-16. http://www.westga.edu/ distance/ojdla/

Opatokun, K. N., Hasim, N. C., \& Hassan, S. S. S. (2013). Authentic leadership in higher learning institution: A case study of International Islamic University Malaysia (IIUM). International Journal of Leadership Studies, 8(1), 49-66. https://www.regent.edu/acad/global/publications/ijls/new/home.htm

Patton, M. Q. (2015). Qualitative research and evaluation methods (4th ed.). Sage. Paolucci, R., \& Gambescia, S. F. (2007). Current administrative structures used for online program offerings in higher education. Online Journal of Distance Learning Administration, 10(3). http://www.westga.edu/ distance/ojdla/

Pennisi, L. (2012). Experiencing the impact of organizational structure on planning and vision tasks. Schole: A Journal of Leisure Studies and Recreation Education, 1, 46-54. https://doi.org/10.1080/1937156X.2012.11949365 
Reid, P. (2018, December 10). EdTechs and instructional designers-What's the difference? Educause Review. https://er.educause.edu/articles/2018/12/edtechs-and-instructional-designerswhats-the-difference.

Saldaña, J., \& Omasta, M. (2017). Qualitative research: Analyzing life. Sage.

Shaw, K. (2012). Leadership through instructional design in higher education. Online Journal of Distance Learning Administration, 15(3).

http://www.westga.edu/ distance/ojdla/fall153/shaw153.html

Shenton, A. K. (2004). Strategies for ensuring trustworthiness in qualitative research projects. Education for Information, 22, 63-75. https://doi.org/10.3233/EFI-2004-22201

Tran, Q., \& Tian, Y. (2013). Organizational structure: Influencing factors and impact on a firm. American. Journal of Industrial and Business Management, 3, 229-236.

https://doi.org/10.4236/ajibm.2013.32028 


\section{Appendix A}

\section{Dedicated Instructional Designer Interview Protocol}

Thanks for your willingness to participate in this interview. By consenting to this interview, you agree to answering the questions honestly, but may choose not to answer any questions that make you feel uncomfortable. All responses and recordings will be de-identified and kept confidential to protect your identity.

1. Please share with me your position title and an overview of your typical responsibilities in that role, including any major tasks, projects, or initiatives that would help clarify your role.

2. Why did you choose to pursue a professional interest or career in online learning for higher education?

3. Does the organizational structure that your university operates within contribute to your success within the organization? In what ways?

4. Does the organizational structure that your university operates within inhibit your success within the organization? In what ways?

5. What are some of the most important initiatives that your university is pursuing, from your own perspective as a professional?

6. How clearly defined are the roles for online learning administrators and dedicated instructional designers at your institution?

7. Are the relationships between administrators and faculty at your institution positive? If so, why?

8. Are the relationships between administrators and faculty at your institution negative? If so, why?

9. When was the last time your institution restructured its online learning and instructional design teams and resources? What were the reasons?

10. Would you like to see anything change in regard to online learning at your institution? If so, what changes would you like to see?

11. Why did your organization choose to structure your instructional design and online learning resources the way that they did?

12. From your perspective, who should have primary decision making authority over online learning initiatives?

13. What kind of leadership role do your administrators, faculty, and dedicated instructional designers play at this institution?

14. How does your organization make decisions regarding curriculum?

15. What system or model do you use to evaluate student growth on learning outcomes and the quality of your courses and curricula?

16. How do dedicated instructional designers at your institution work with faculty on courses and curriculum?

17. What is your experience working as a dedicated instructional designer?

18. What are the most challenging parts of working with your administration?

19. What are the most challenging parts of working with your faculty?

20. Do your administrators work to ensure the dedicated instructional designers have an equal seat at the table for major decisions around online learning initiatives? If so, what in particular do they do?

21. Does collaboration happen between administrators, faculty, and dedicated instructional designers when creating a new online program? If so, how would you characterize it?

22. What do faculty and administrators at your institution do that empowers or disempowers you? 


\section{Appendix B}

\section{Online Faculty Member Interview Protocol}

Thanks for your willingness to participate in this interview. By consenting to this interview, you agree to answering the questions honestly, but may choose not to answer any questions that make you feel uncomfortable. All responses and recordings will be de-identified and kept confidential to protect your identity.

1. Please share with me your position title and an overview of your typical responsibilities in that role, including any major tasks, projects, or initiatives that would help clarify your role.

2. Why did you choose to pursue a professional interest or career in online learning for higher education?

3. Does the organizational structure that your university operates within contribute to your success within the organization? In what ways?

4. Does the organizational structure that your university operates within inhibit your success within the organization? In what ways?

5. What are some of the most important initiatives that your university is pursuing, from your own perspective as a professional?

6. How clearly defined are the roles for online learning administrators and dedicated instructional designers at your institution?

7. Are the relationships between administrators and faculty at your institution positive? If so, why?

8. Are the relationships between administrators and faculty at your institution negative? If so, why?

9. When was the last time your institution restructured its online learning and instructional design teams and resources? What were the reasons?

10. Would you like to see anything change in regards to online learning at your institution? If so, what changes would you like to see?

11. Why did your organization choose to structure your instructional design and online learning resources the way that they did?

12. From your perspective, who should have primary decision making authority over online learning initiatives?

13. What kind of leadership role do your administrators, faculty, and dedicated instructional designers play at this institution?

14. How does your organization make decisions regarding curriculum?

15. What system or model do you use to evaluate student growth on learning outcomes and the quality of your courses and curricula?

16. How do dedicated instructional designers at your institution work with faculty on courses and curriculum?

17. What is your experience working as a dedicated instructional designer?

18. What are the most challenging parts of working with your administration?

19. What are the most challenging parts of working with your faculty?

20. Do your administrators work to ensure the dedicated instructional designers have an equal seat at the table for major decisions around online learning initiatives? If so, what in particular do they do?

21. Does collaboration happen between administrators, faculty, and dedicated instructional designers when creating a new online program? If so, how would you characterize it?

22. What do faculty and administrators at your institution do that empowers or disempowers you? 


\section{Appendix C}

\section{Online Learning Administrator Protocol}

Thanks for your willingness to participate in this interview. By consenting to this interview, you agree to answering the questions honestly, but may choose not to answer any questions that make you feel uncomfortable. All responses and recordings will be de-identified and kept confidential to protect your identity.

1. Please share with me your position title and an overview of your typical responsibilities in that role, including any major tasks, projects, or initiatives that would help clarify your role.

2. Why did you choose to pursue a professional interest or career in online learning for higher education?

3. Does the organizational structure that your university operates within contribute to your success within the organization? In what ways?

4. Does the organizational structure that your university operates within inhibit your success within the organization? In what ways?

5. What are some of the most important initiatives that your university is pursuing, from your own perspective as a professional?

6. How clearly defined are the roles for online learning administrators and dedicated instructional designers at your institution?

7. Are the relationships between administrators and faculty at your institution positive? If so, why?

8. Are the relationships between administrators and faculty at your institution negative? If so, why?

9. When was the last time your institution restructured its online learning and instructional design teams and resources? What were the reasons?

10. Would you like to see anything change in regard to online learning at your institution? If so, what changes would you like to see?

11. Why did your organization choose to structure your instructional design and online learning resources the way that they did?

12. From your perspective, who should have primary decision making authority over online learning initiatives?

13. What kind of leadership role do your administrators, faculty, and dedicated instructional designers play at this institution?

14. What system or model do you use to evaluate student growth on learning outcomes and the quality of your courses and curricula?

15. How do dedicated instructional designers at your institution work with faculty on courses and curriculum?

16. What do you consider to be the most important role for dedicated instructional designers at your institution?

17. What are the most challenging parts of working with your faculty?

18. What are the most challenging parts of working alongside a dedicated instructional designer?

19. What do your administrators do to ensure the dedicated instructional designers have an equal seat at the table for major decisions around online learning initiatives?

20. Does collaboration happen between administrators, faculty, and dedicated instructional designers when creating a new online program? If so, how would you characterize it? 